Çukurova Üniversitesi Mühendislik Mimarlık Fakültesi Dergisi, 31(ÖS 1), ss. ÖS 19-ÖS 27, Ağustos 2016 Çukurova University Journal of the Faculty of Engineering and Architecture, 31(ÖS 1), pp. SI 19-SI 27, August 2016

\title{
Termoplastiklerin Sürtünme Karıştırma Kaynağı ile Birleştirilmesinde Kullanılan Yöntemler
}

\author{
İdris KARAGÖZ ${ }^{* 1}$, Mustafa ÖKSÜZ ${ }^{2}$ \\ ${ }^{1}$ Yalova Üniversitesi, Yalova Meslek Yüksekokulu, Malzeme ve Malzeme İşleme Teknolojileri \\ Bölümü, Yalova \\ ${ }^{2}$ Yalova Üniversitesi, Mühendislik Fakültesi, Polimer Mühendisliği Bölümü, Yalova
}

Geliş tarihi: 24.12.2015 Kabul tarihi: 30.03 .2016

\section{Özet}

Plastiklerin kaynakla birleştirilmesinde sürtünme karıştırma kaynağı (SKK) diğer kaynak yöntemlerine oranla oldukça yeni bir kaynak tekniğidir. Metal ve alaşımlarına kıyasla, plastiklerin birleştirilmesinde sürtünme karıştırma kaynağının kullanımı endüstriyel olarak henüz yaygınlaşmamıştır. $\mathrm{Bu}$ çalışmada plastikler için uygulanan mevcut sürtünme karıştırma kaynak yöntemleri derlenmiştir. Mevcut yöntemlerle yapılan çalışmaların sonuçları incelenerek birbiri ile karşılaştırılmış ve endüstriyel olarak uygulanabilirlikleri ve avantajları ön plana çıkartılmaya çalışılmıştır. Ayrıca yöntemin uygulanması ile ilgili olarak mevcut çalışmalar ışığında yapılan öneriler ve sonuçların değerlendirilmesiyle geliştirilmeye en uygun sürtünme karıştırma kaynak yöntemi tespit edilmeye çalışılmıştır.

Anahtar Kelimeler: Sürtünme karıştırma kaynağ1, Termoplastiklerin kaynağ1, Birleştirme, Sürtünme karıştırma nokta kaynağı, Kaynaklı birleştirmeler

\section{Methods Used In Joining Thermoplastics By Friction Stir Welding}

\begin{abstract}
Joining thermoplastics by friction stir welding (FSW) is a pretty new method compared to other welding methods. When compared to metals and alloys joining plastics by friction stir welding has not become industrially widespread. In this study the existing friction stir welding methods used for plastics were compiled. The results of the studies made by existing methods were examined and compared with each other and their advantages as well as industrially applicabilities were emphasized. Besides a friction stir welding method which is most suitable for development was determined by evaluating the suggestions and results in light of the current studies related with application of the method.
\end{abstract}

Keywords: Friction stir welding, Joining plastics, Friction stir spot welding, Joining sheets, Methods used in joining thermoplastics

\footnotetext{
* Sorumlu yazar (Corresponding author) : İdris KARAGÖZ, Yalova Meslek Yüksekokulu, Malzeme ve Malzeme İşleme Teknolojileri Bölümü, Yalova. idris_karagoz@yalova.edu.tr
} 


\section{GíRiş}

Termoplastiklerin kaynağında kullanılan bazı kaynak teknikleri, sıcak gaz kaynağında olduğu gibi metal kaynak tekniklerine benzemektedir. Metal ve plastiklerin sahip olduğu özellikler birbirinden farklılık göstermekte ve metallere uygulanan bir kaynak yönteminin plastiklere uygulanabilir hale getirilmesi için pek çok çalışma yapılmaktadır. Metal kaynak teknikleri arasında yer alan sürtünme karıştırma kaynağı (SKK), başlangıçta alüminyum alaşımlarının kaynağı için geliştirilerek patenti alınan ve plastiklere uygulanması için üzerinde çalışmalar yapılan bir kaynak yöntemidir.

Metal ve alaşımları için SKK endüstriyel olarak uygulanabilmekte, ancak metallerin aksine plastikler için SKK, plastiklerin termal ve viskoelastik özelliklerine bağlı olarak sınırlı kalmaktadır [1,2]. Metallerden farklı olarak Şekil 1'de görüldüğü gibi termoplastiklere SKK bir kaç farklı yöntem ile uygulanmaktadır. Termoplastiklere uygulanan SKK'ını, Geleneksel SKK, Dikey Hareketli SKK, Titreşim-Sürtünme SKK ve Sürtünme Karıştırma Nokta Kaynağı (SKNK) şeklinde sınıflandırmak mümkündür [2].

\section{KAYNAK YÖNTEMLERININ SINIFLANDIRILMASI}

\subsection{Geleneksel Sürtünme Karıştırma Kaynağı}

Metallerde olduğu gibi plastikler içinde SKK yönteminin uygulanması oldukça basittir.
Birleștirilmek üzere sabitlenmiş plaka, boru vb. malzemelerin kaynak bölgesine sabit devirde silindirik omza sahip bir takım daldırılır ve kaynak yapılacak hat boyunca sabit ilerleme hızı ile hareket ettirilir. Kaynak bileşenlerinin (kaynak takımı ve malzeme) sürtünmesiyle kaynağın gerçekleştirilmesi için gerekli olan 1sı meydana gelir ve oluşan bu 1sı malzemeyi yumuşatır. Kaynak takımının omzu, pim tarafindan yumuşatılarak geriye atılan malzemelere bask1 uygulayip kontrol ederek malzemelerin kaynaklanmasında rol oynar [1-3]. Şekil 2'de Termoplastiklerin SKK ile birleştirilmesi ve oluşan mikroyapılar şematik olarak gösterilmektedir.

Geleneksel SKK yönteminde 1S1 girdisinin iyi sağlanması gerekmektedir. Yapılan çalışmalar incelendiğinde düşük devirde takım tarafından kaynak bölgesine yüksek basınç kuvveti uygulanmazsa ya da ilerleme hızı yüksek olarak seçilmiş ise etkin 1sı girdisi sağlanamamaktadır. $\mathrm{Bu}$ durumda yeterli 1 S1 elde edilemediği için malzeme yumuşatılamamakta ve pim tarafından arka tarafa yeterli malzeme taşınamadığı için de kaynak mukavemeti zayıf olmaktadır. Kaynak bölgesine yüksek 1s1 girdisi, takım omzunun malzeme yüzeyine daha fazla baskı uygulaması, yüksek devir ve düşük ilerleme hızı ile sağlanabilmektedir. Takım omzu tarafindan malzemeye daha yüksek baskı kuvveti uygulanması 1S1 girdisini arttırmakta ancak kaynaklı bölgede aşırı deformasyon oluşturarak malzeme kaybına neden olmaktadır. Bu durum kaynaklı bağlantının mukavemetini zayıflatmaktadır.

Termoplastiklerin

Sürtünme Karıştırma Kaynağı

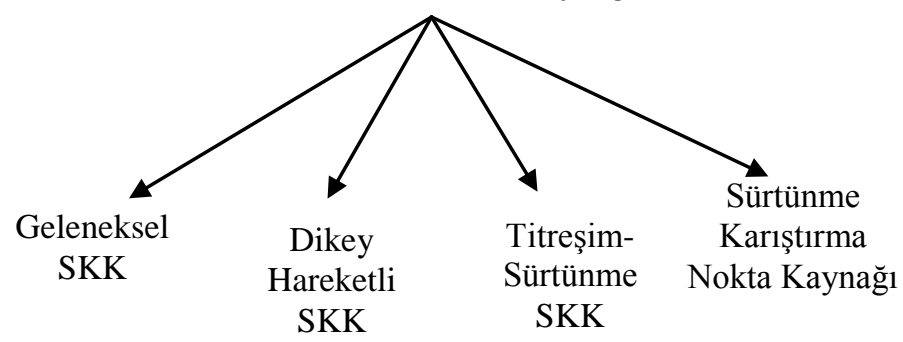

Şekil 1. Termoplastiklere uygulanan sürtünme karıştırma kaynak yöntemlerinin sınıflandırılması 


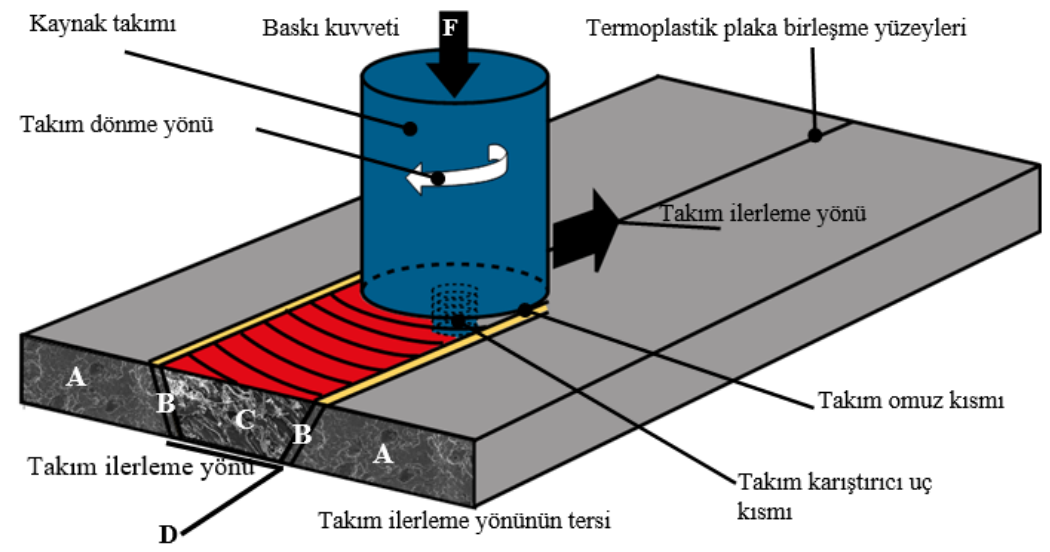

Şekil 2. Termoplastiklerin SKK ile birleştirilmesinin ve oluşan mikroyapıların şematik gösterimi, AIsıdan etkilenmeyen bölge (ana malzeme), B- Birleşme ara yüzeyi, C- Termomekanik olarak etkilenen karışım bölgesi, D- Birleştirilmeyen kaynak takımı karıştırıcı uç kısmı altında kalan bölge

Devir sayısının ve ilerleme hızının arttırılması yüksek baskı kuvveti ile elde edilen 1sı girdisini sağlamakta ve kaynaklı bölgede malzeme yüzeyi daha az deformasyona uğramaktadır. Düşük ilerleme hızlarında kaynak yapma süresinin artması, kaynak maliyetini arttırmaktadır. Araştırmacılar geleneksel SKK yönteminin plastiklere uygulanmasında aşağıdaki problemlerle karşılaşıldığını ifade etmişlerdir [1-9]:

- Birleştirme bölgesinde malzeme tutulmasındaki zorluk nedeniyle kaynak yapısında boşluk meydana gelmesi,

- Kaynak hızlarının oldukça düşük olması

- Kaynak bölgesinde polimerin karıștırılmasındaki zorluklar,

- Üniform olmayan bir kaynak yüzeyi ya da plastiğin küçük parçalar şeklinde birbiri ile kaynamas1,

- Zayıf kaynak mukavemeti,

- Kaynak için gerekli olan ısının elde edilmesinde ve taşınmasındaki zorluklar.

Araştırmacılar tarafından yukarıda ifade edilen problemlerin giderilmesi amacıyla, kaynak takımı omuz kısmına eğim verilmesi $[1,4,6,10]$, takım dönme devrinin arttırılması [10,12], takım omuz kısmının bilyeli olarak tasarlanması ve kaynak bölgesindeki deformasyonun önlenmesi [9,12], takım karıştırıcı uç geometrisinin farklı geometrik profillerde tasarlanması [7], kaynak bölgesine dışarıdan 1Sı verilmesi gibi farklı yöntemler ve kaynak takımları geliştirilmiştir [3,9]. Düşük hızlarda yapılan çalışmalar arasında en iyi sonuçlar Nelson, Strand ve Johns tarafindan benzer şekilde geliştirilen ve sıcak pabuç olarak isimlendirilen takım ile alınmıştır. Şekil 3'te Nelson tarafından geliştirilen sıcak pabuç tasarımlı kaynak takımı gösterilmektedir. Ancak bu takım tasarımı ile yapılan birleştirme işlemlerinde bile istenilen sonuçların tam olarak elde edilemediği ve aşağıdaki sonuçların elde edildiği Johns tarafindan ifade edilmiştir [3]:

1. Pim çapının artmasına paralel olarak, kaynak bağlantı mukavemetinin arttığ1,

2. İlerleme hızının artmasıyla bağlantı mukavemetinin arttığı ancak belli bir ilerleme hizından sonra (305 $\mathrm{mm} / \mathrm{dk}$.) bağlantı mukavemetinde kayda değer bir artış sağlanamadığı,

3. Pabuç sıcaklığının artmasıyla kaynak mukavemetinin de arttı̆̆ 1 ,

4. Malzeme yüzeyine uygulanan basınç süresi ile ilgili olarak net bir verinin elde edilemediği.

Yukarıda yapılan çalışmalardan farklı olarak Karagöz ve Öksüz tarafından CNC dik işleme 
merkezinde kaynak takımına malzeme türüne göre değişiklik göstermekle birlikte $3000-6000$ devir/dk yüksek devirler uygulanmış ve Polietilen (PE) için \%96, PP için \%85 oranında ana malzemenin mukavemetine yakın oldukça başarılı sonuçlar alınmıştır [1]. Malzeme yüzeyinde takım omuz kısmının yaptı̆̆ 1 baskı ayarlanarak oluşan deformasyon önlenmiş ve kaynakta mukavemet kaybının önüne geçilmiştir. Şekil 4'te yüksek devir hızlarında $\mathrm{CNC}$ dik işleme merkezinde uygulanan birleştirme işlem sırası ve kaynaklı levhalar gösterilmiştir.

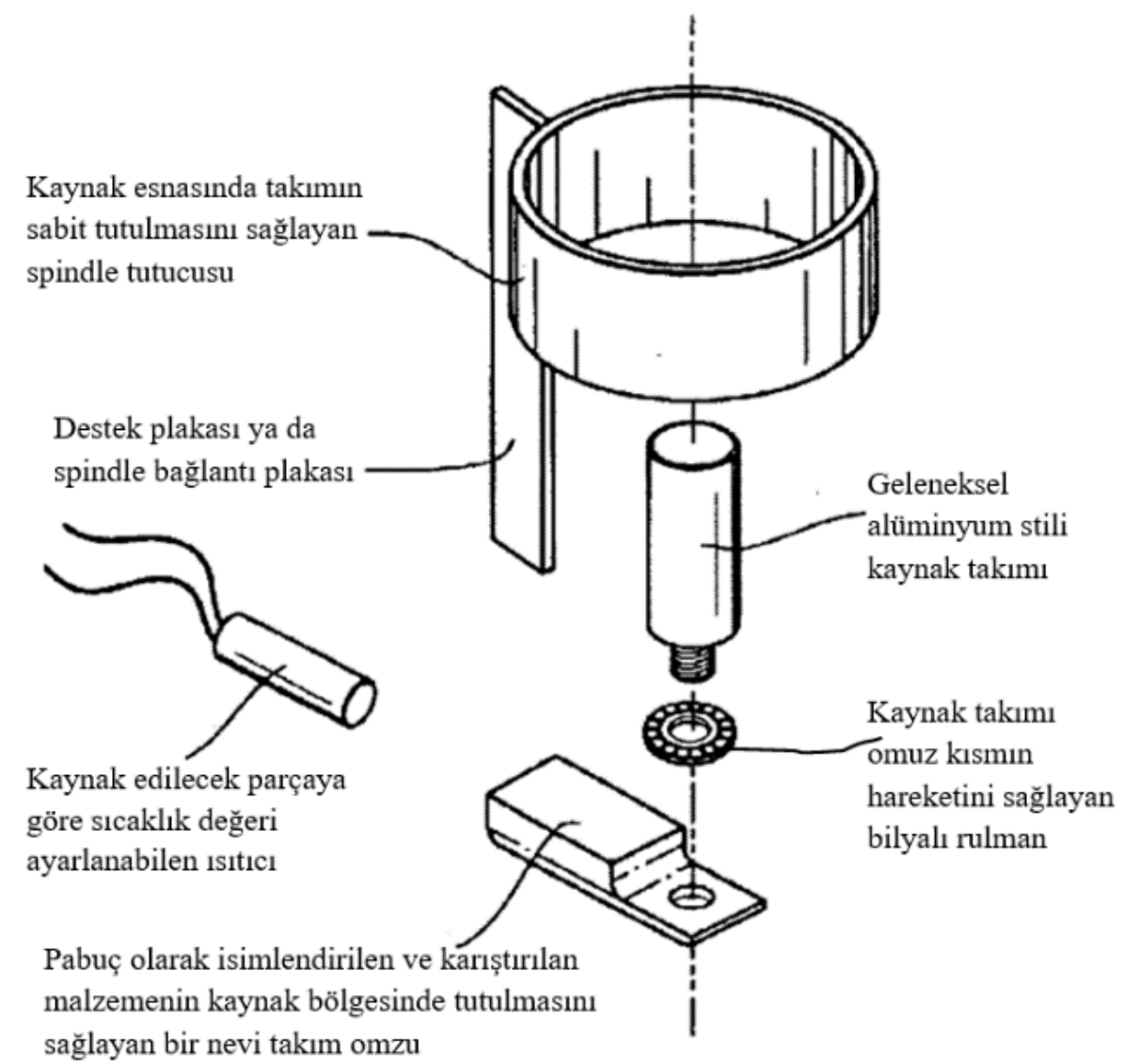

Şekil 3. Nelson tarafından geliştirilen SKK kaynak takımı [9]

\subsection{Dikey Hareketli Sürtünme Karıştırma Kaynağı (DHSKK)}

Dikey hareketli sürtünme karıştırma kaynağının uygulanması Şekil 5'te gösterildiği gibidir. Sistem kaynak takımı pim ve omzundan oluşan silindirik bir takım yerine aşağı ve yukarı olmak üzere dikey yönde hareket eden bıçak şeklinde yassı bir takımdan oluşur [5]. Bıçak şeklindeki takım birleştirilmek üzere sabitlenmiş plaka, boru vb. malzemelerin kaynak bölgesine daldırılır ve kaynak yapilacak hat boyunca sabit bir ilerleme hızı ile hareket ettirilir. Kaynak için gerekli olan 1sı plastik malzeme ve bıçak şeklindeki yassı takımın birbiri ile sürtünmesiyle elde edilir. Kaynak bileşenlerinin (kaynak takımı ve malzeme) sürtünmesiyle kaynağın gerçekleştirilmesi için gerekli olan 1s1 meydana gelir ve oluşan bu 1s1 malzemeyi yumuşatır. 

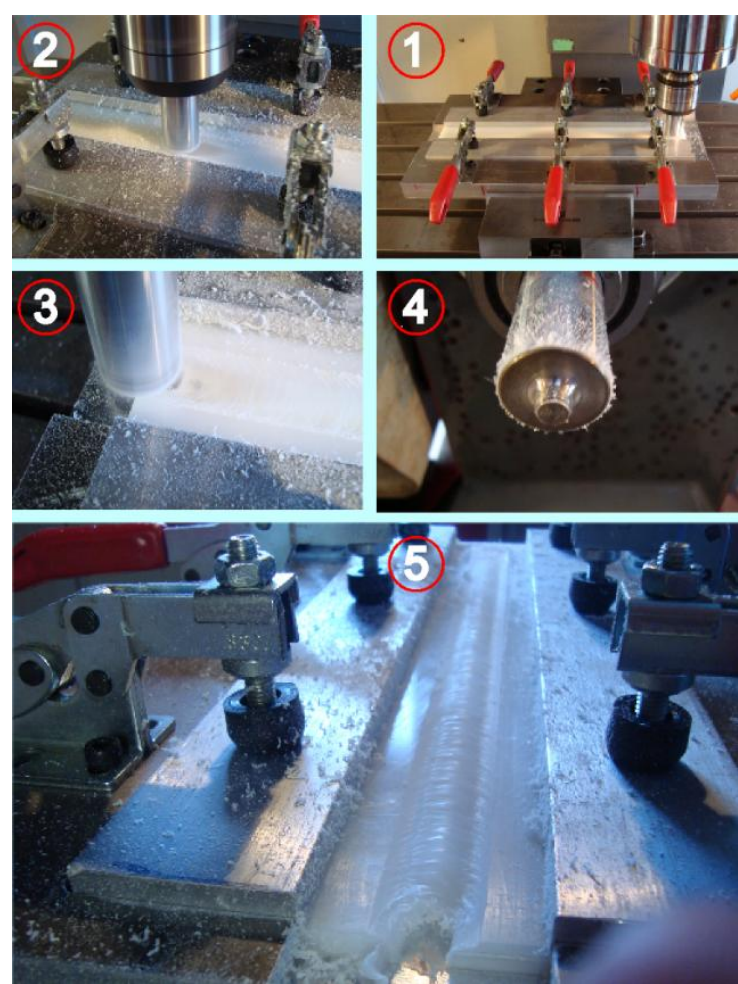

Şekil 4. CNC dik işleme merkezinde SKK uygulama işlem adımları, 1- Birleştirilecek parçalara kaynak takımının daldırılması, 2- Sabit bir hızda kaynak hattı boyunca kaynak takımının ilerletilmesi, 3Kaynağın sonlandırılması, 5- Kaynak takımının yukarı çekilmesi, 5- SKK ile birleştirilmiş malzemelerin bağlama kalıbında bekletilmesi [1]

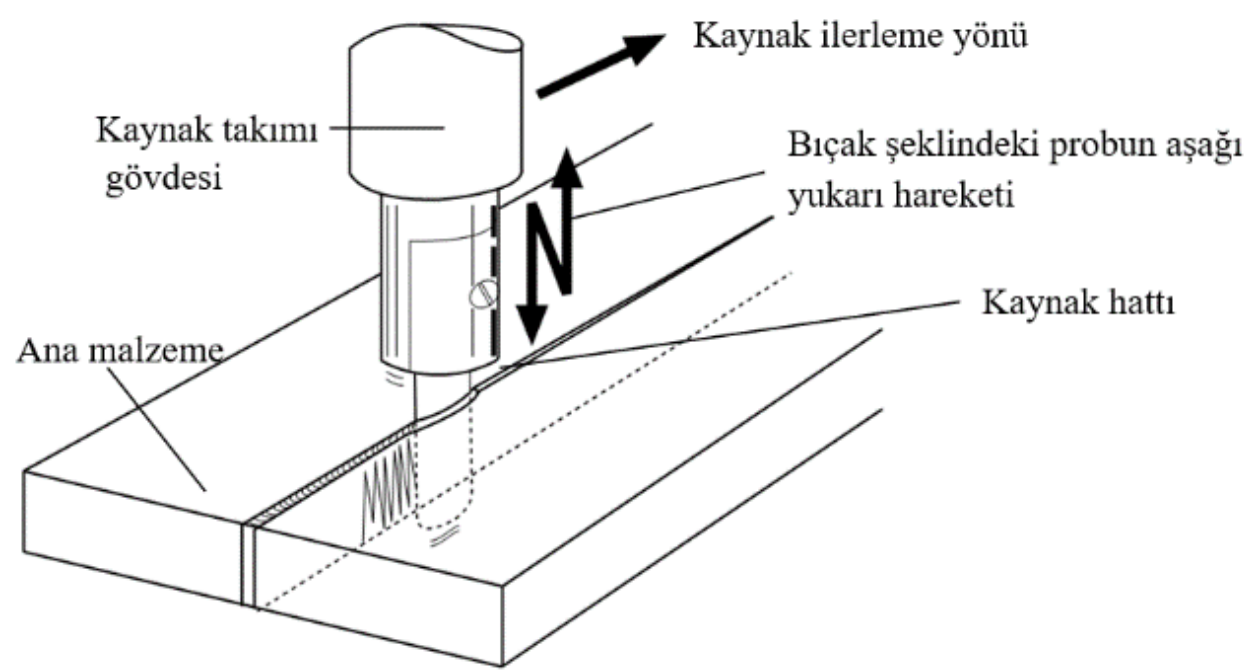

Şekil 5. Dikey hareketli SKK uygulamasının şematik gösterimi [5] 
Panneerselvam ve arkadaşları tarafindan $2 \mathrm{~mm}$ kalınlığında akrilik malzemelere DHSKK uygulanmış ve kaynak bağlantısının mukavemeti ve kalitesi yapısal ve mekanik çalışmalarla analiz edilmiştir. Araştırmacılar malzeme kalınlığının, kaynak probunun (bıçağının) kalınlığı ve geometrisinin, kaynağa etkiyen parametreler olduğunu ifade etmişlerdir. Uygulamalarda termomekanik olarak etkilenen kaynak bölgesinde gözenekli bir yap1 meydana geldiği, malzeme akışının yetersiz olduğu ve bununda kaynak mukavemetini azalttığını ifade etmişlerdir [13]. Bu yöntemin en temel problemi erimiş malzemeyi kaynak bölgesinde tutacak bir mekanizmanın olmamasıdır. Erimiş malzeme kaynak bölgesinde tutunamadığı için kaynak bölgesinde boşluklar oluşmakta ve buna bağlı olarak zayıf kaynak mukavemeti elde edilmektedir. Erimiş plastiği kaynak bölgesinde tutacak bir mekanizmanın geliştirilmesi kaynak mukavemetini arttıracaktır. Mevcut durumda bu yöntem çok fazla uygulanabilir değildir ve bu nedenle çok fazla yaygınlaşmamıştır.

\subsection{Titreșim-Sürtünme Yöntemi ile Sürtünme Karıştırma Kaynağı}

Yukarıda bahsedilen kaynak yöntemleriyle istediği sonuçları elde edemeyen İngiliz Kaynak Enstitüsü (TWI) tarafından geliştirilmiş yeni bir yöntemdir. Uygulama itibari ile dikey hareketli SKK'nna benzemektedir. $\mathrm{Bu}$ proseste ileri geri hareket ederek titreşim oluşturan ve kaynak hattına paralel ilerleyen bıçak şeklinde yassı bir takım ve bir omuzdan oluşan montajlı bir kaynak takımı kullanılır. Kaynak için gerekli olan 1sı, plastik malzeme ile bıçak şeklindeki yassı takım ve takım omzunun malzeme yüzeyleri ile sürtünmesinden elde edilir. Elde edilen 1s1 dikey kuvvet altında takımın hareket ettiği kenarların kalınlığı boyunca malzeme yüzeyini eritir ve takımın ilerleme hareketiyle arkada kalan bölgede birleștirme işlemi gerçekleştirilmiş olur [2]. Yöntemin uygulanması Şekil 6'da şematik olarak gösterilmiştir.

Kaynak başlangıcında plastiklerin sahip olduğu düşük 1S1 iletkenliğinden dolayı omuz tarafindan üretilen 1s1, kaynak merkezine yakın malzemenin eritilmesi için yeterli değildir. $\mathrm{Bu}$ yüzden alın kaynağında, yüzeylerin birleştirilmesi için ihtiyaç duyulan ısının tamamı bıçak şeklindeki yassı takım tarafından oluşturulmalıdır. Yöntemin uygulanmasında iki temel adım vardır:
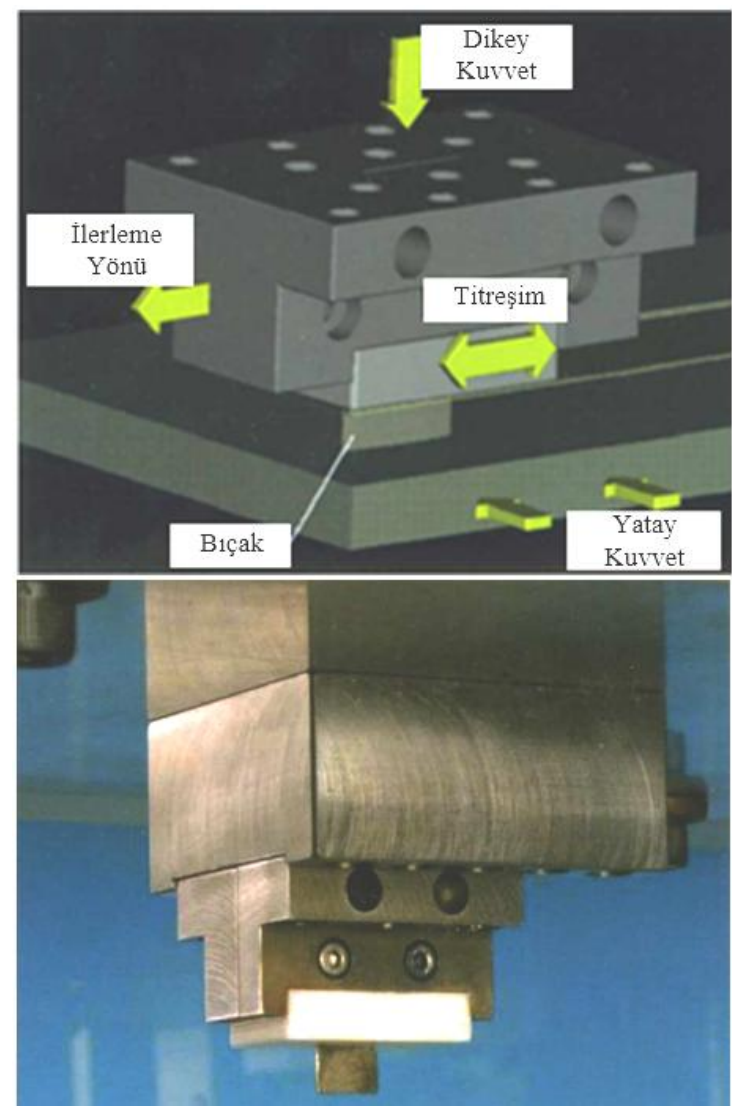

Şekil 6. Titreşim-Sürtünme yöntemi ile plastik malzemelere SKK uygulanması [2]

1- Kaynak için gerekli olan 1S1, bıçak şeklindeki yassı takım ve plastik levhalar arasındaki sürtünmeden dolayı elde edilir.

2- Kaynaklı birleştirmenin gerçekleşmesi ve kaynak bölgesinde elde edilen isının korunması için parçalar ile takım temasının devam ettirilmesi yani sürekli olarak bir temasın sağlanması gerekmektedir.

Omuz tarafindan uygulanan dikey yük, plaka üst yüzeylerinde malzemeleri eritmek için bir 1S1 
girdisi oluşturur ancak takım omzunun kaynaklı parçaların birbiri ile temas ettiği birleştirme yüzeylerine direkt olarak etkisi yoktur. Yöntemde uygulanan yatay kuvvet üç farklı bileşenle tanımlanır. Yatay kuvvetin uygulanmasına bağlı olarak, birleştirme işlemi için malzemenin 1sitılmasıyla ısıl genleşme meydana gelir. Bıçağın ilerleme hareketi ile bıçak şeklindeki yassı takımın çevresinde açığa çıkan ergimiş haldeki plastik malzemeler birbiri ile kaynatılır. Yatay kuvvetin uygulanması, bıçağın ilerleme hareketi ve biçak şeklindeki yassı takımın yüzeyleriyle malzemelerin sürtünmesinin sonucu olarak doğrudan 1S1 oluşturulur. Birleştirilmek üzere sabitlenmiş parçaların temas yüzeyleri arasındaki baskı kuvveti, bıçak şeklindeki yassı takımın ilerlemesi ve buna bağlı olarak oluşan yatay kuvvet ve 1sıl genleşmenin etkisi ile oluşturulur.

$\mathrm{Bu}$ yöntemin en önemli avantajı, kaynak takım ucunun sürekli kaynak bölgesinde olması ve erimiş malzemenin kolayca kaynak bölgesinde tutulmasını sağlayan bir sistemin olmasıdır. Dikey hareketli sürtünme karıştırma kaynağı ile karşılaştırıldığında, kaynak bölgesinde elde edilen ortalama sıcaklık daha yüksektir ve sistemdeki 1sı kayıpları önemli derecede azaltılmıştır.

Scialpi ve arkadaşları tarafından titreşim-sürtünme yöntemi ile düşük $(1270 \mathrm{~N})$ ve yüksek $(2400 \mathrm{~N})$ dikey kuvvet etkisi altında PP malzemelere SKK uygulanmıştır. Kaynak sonrası kaynak parametrelerinin kaynak mukavemeti üzerindeki etkileri incelenmiştir. Araştırmalar tarafindan elde edilen sonuçlar şu şekilde açıklanmıştır [2]:

1- Kaynakta kullanılan takımın sahip olduğu özellikler (boyu, bıçak kalınlığı vb.) mekanik özellikleri önemli ölçüde etkilemektedir. Bıçak kalınlığının azaltılması diğer kaynak parametrelerinden bağımsız olarak mekanik özelliklerde artış sağlamaktadır.

2- Yatay kuvvet kaynak görünümü üzerinde oldukça etkili olmaktadır. Üst yüzeye aşırı yatay kuvvet uygulanması, kaynak hattı üzerinde malzemeyi şişirerek baloncuk (gaz boşluğu) oluşturmaktadır.

3- Yatay kuvvet ve bıçak boyu kaynak bölgesinde elde edilen sıcaklık üzerinde etkili olmaktadır. Yatay kuvvetin yüksek olması, birleştirilen levha kalınlıklarına göre bıçak boyunun doğru ayarlanamaması kaynak hattı üzerinde aşırı baloncuk (gaz boşluğu) oluşmasına neden olmaktadır.

4- Yapılan eğme deneylerinde, kaynak kök bölgesinde bıçak uzunluğu hariç tüm parametrelerin (bıçak kalınlığı, düşey yük ve yatay kuvvet) etkisi olumsuzdur.

5- Dikey kuvvetin yüksek olması, sürtünmeyle birlikte kaynak bölgesindeki 1sıyı artırarak eriyen malzeme miktarını da artıracaktır.

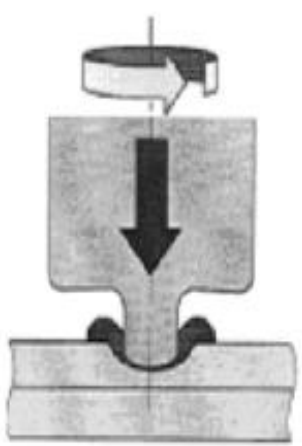

1 - Dalma

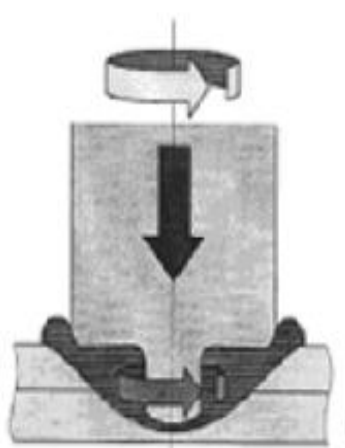

2 - Karıștırma

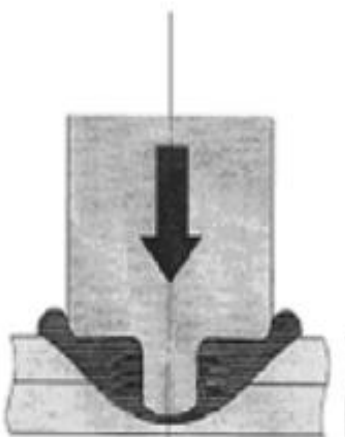

3 - Katılașma

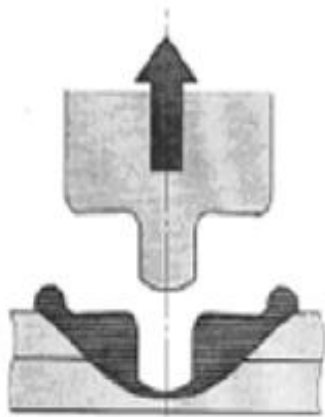

4-Geri Çekme

Şekil 7. SKNK uygulamasında kaynak işlem adımları [14] 


\subsection{Sürtünme Karıştırma Nokta Kaynağı}

Sürtünme karıştırma nokta kaynağı (SKNK), geleneksel yöntemlerle birleştirilmesi zor ve masraflı olan demir dışı metallerin birleştirilmesi amacıyla ortaya çıkan ve son zamanlarda plastikler içinde başarılı bir şekilde uygulanan bir birleştirme yöntemidir. Uygulama şekli itibari ile SKK'ına benzemektedir. 2001 y1lında alüminyum alaşımlarının nokta kaynak yöntemi ile birleştirilmesi amacıyla otomotiv endüstrisi tarafından geliştirilmiştir. SKNK kullanılan kaynak takım omuz çapı daha geniş, karıştırıcı uç (pim) çapı ise daha küçük olacak bir tasarım yapılmaktadır. Şekil 7'de gösterildiği gibi SKNK plastiklere 1-Dalma, 2-Karıştırma, 3-Katılaşma, 4- Geri Çekme olmak üzere dört adımda uygulanmaktadır.

$\mathrm{Bu}$ yöntemle yapılan çalışmalar incelendiğinde araştırmacılar tarafından takım dönme hızının artmasıyla kaynak bölgesindeki 1sının arttı̆̆ 1 , belirli bir süre sonra sürtünme katsayısının azalmasına bağlı olarak kaynak bölgesinde sıcaklığın sabit hale geldiği, kaynak bölgesinde bekleme süresinin kaynak mukavemeti ve kaynak kalitesi üzerinde etkili olduğu ifade edilmiştir $[14,15]$.

\section{SONUÇLAR VE ÖNERÍLER}

Genel hatlarıyla mevcut tüm çalışmalar incelendiğinde başarılı bir SKK uygulamasının önündeki en büyük engelin kaynak için gerekli olan ısının elde edilmesi ve taşınmasındaki zorluklar olduğu görülmektedir. $\mathrm{Bu}$ sorunun çözümüne yönelik olarak araştırmacılar tarafindan daha önceki bölümlerde bahsedilen farklı uygulama teknikleri ve kaynak takımları geliştirilmiştir. $\mathrm{Bu}$ yöntem ve takımlar arasında en iyi sonuçların yüksek takım dönme ve ilerleme hızlarında CNC kontrollü olarak yapılan ve klasik alüminyum stili kaynak takımlarının kullanıldığ yöntemle ve ön 1sitmalı pabuç kullanilan geleneksel SKK yöntemleriyle elde edildiği görülmüştür.
Yöntemin plastikler için endüstriyel olarak uygulanabilmesi ancak yüksek devirlerde CNC kontrollü makinelerle yapilan uygulamalarla mümkün olmaktadır. Düşük devirli üniversal tezgahlarla yapılan uygulamaların kaynak mukavemeti ve kaynak yüzey kalitesi üzerindeki etkisi oldukça sınırlı olmakta ve olumsuz sonuçlar elde edilmektedir. Mevcut durumda yeni çalışmaların yüksek devirler kullanılarak yapılması yöntemin endüstriyel olarak kullanımını yaygınlaştıracak ve ülkemiz ekonomisine bir katma değer yaratacaktır. Ancak bunun öncesinde birleştirilecek malzeme türü, kalınlığı, kaynak mesafesi vb. parametrelere ait optimizasyon çalışmalarının yapılması ve uygulamalara ait bir veri havuzunun oluşturulması gerekmektedir. Ancak bu sayede mevcut sorunlara ya da yeni ürün geliştirme çalışmalarına geniş bir perspektiften çözüm önerileri sunulabilecektir.

\section{KAYNAKLAR}

1. Karagöz, İ., 2014. Termoplastiklerin Sürtünme Karıştırma Kaynak Özellikleri, Doktora Tezi, Marmara Üniversitesi, Fen Bilimleri Enstitüsü, Göztepe, İstanbul-Türkiye.

2. Scialpi, A. Troughton, S., Andrews, S., Filippis L., 2009. Viblade ${ }^{\mathrm{TM}}$-Friction Stir Welding For Plastic, Welding International, 23-11, pp. 846855.

3. Strand, S.R., 2004. Effects of Friction Stir Welding On Polymer Microstructure, Master of Science, Brigham Young University Department of Mechanical Engineering Utah, USA.

4. Şelale, S., 2006. Polietilen Malzemenin Sürtünme Karıştırma Kaynağı ile Birleştirilmesi, Yüksek Lisans Tezi, Kocaeli Üniversitesi Fen Bilimleri Enstitüsü, Kocaeli, Türkiye.

5. Troughton, M., 2008. Handbook of Plastics Joining A Practical Guide, 2nd Edition, Published William Andrew Inc., USA.

6. Bozkurt, Y., 2012. The Optimization of Friction Stir Welding Process Parameters to Achieve Maximum Tensile Strength in Polyethylene Sheets. Material and Design, 35, pp. 440-445. 
7. Ahmadi, H., Arab, N.B.M., Ghasemi, F.A., Farsani, R.E., 2012. Influence of Pin Profile on Quality of Friction Stir Lap Welds in Carbon Fiber Reinforced Polypropylene Composite. International Journal of Mechanics and Applications, 2-3, pp. 24-28.

8. Czigány, T., Kiss, Z., 2011. Friction Stir Welding Of Fiber Reinforced Polymer Composites. 18th International Conference On Composite Materials, 21-26 August, Jeju Island, Korea.

9. Nelson, W.T., Sorenson, C.D., Johns, C.J., 2004. Friction Stir Welding of Polymeric Materials. United States Patent US 6, 811,632 B2, November 2.

10. Payganeh, G.H., Arab, M., Asl, Y.D., Ghasemi, F.A., Broujeni, M.S., 2011. Effects of Friction Stir Welding Process Parameters on Appearance and Strength of Polypropylene Composite Welds. International Journal of The Physical Sciences, 6-19, pp. 4595-4601.

11. Rezgui, M.A., Ayadi, M., Cherouat, A., Hamrouni, K., Zghal, A., Bejaoui, S., 2010. Application of Taguchi approach to Optimize Friction Stir Welding Parameters of Polyethylene. EPJ Web of Conferences 6 07003.

12. Squeo, E.A., Bruno, G., Guglielmotti, A., Qudrini, F., 2009. Friction Stir Welding of Polyethylene Sheets. The Annals of Dunărea De Jos University of Galati, Fascicle V Technologies in Machine Building 122104566, pp. 241-246.

13. Panneerselvam, K., Aravindan, S., Haq, A.N., 2004. Joining of Plastics By Frictional Vibration. International Symposium of Research Students on Materials Science and Engineering, 20-22 December, Chennai, India.

14. Bilici, M.K., Yükler, A.İ., Fidaner, O., 2012. Termoplastiklerin Sürtünme Karıştırma Nokta Kaynak Birleştirilmesinde Kaynak Parametrelerinin Etkileri. 3. Ulusal tasarım İmalat ve Analiz Kongresi, 29-30 Kasım, Balıkesir, Türkiye.

15. Kurtulmuş, M., 2012. Friction Stir Spot Welding Parameters for Polypropylene Sheets. Scientific Research and Essays, 7-8, pp. 947956. 
